\title{
Neutron Activation Analysis of Some Building Material
}

\author{
T.M. Talaat Salama ${ }^{1}$, N. A. Mansour ${ }^{1}$ and M. Fayez-Hassan ${ }^{2}$ \\ ${ }^{1}$ Zagazig University, Faculty of Science, Physics Department, Zagazig - Egypt \\ ${ }^{2}$ Experimental Nuclear Physics Department, Nuclear Research Center, \\ Egyptian Atomic Energy Authority, Cairo, Egypt. \\ tsalamaphy@yahoo.com
}

\begin{abstract}
Neutron activation analysis (NAA), based on the comparator method, has the potential to fulfill the requirements of a primary ratio method as defined in 1998 by the Comité Consultatif pour la Quantité de Matière - Métrologie en Chimie (CCQM, Consultative Committee on Amount of Substance - Metrology in Chemistry Studies of Neutron Activation Analysis (NAA) have been carried out on different Egyptian building material samples. The technique of neutron activation analysis is based on the measurement of radiation released by the decay of radioactive nuclei formed by neutron irradiation of the material. The most suitable source of neutrons for such an application is usually a research reactor. The samples that can be analyzed with this method stem from a number of different fields, including medicine, nutrition, biology, chemistry, forensics, the environment and mining. Neutron activation analysis can be performed in a variety of ways. This depends on the element and the corresponding radiation levels to be measured, as well as on the nature and the extent of interference from other elements present in the sample. Most of the methods used are non-destructive, based on the detection of gamma radiation emitted by the irradiated material after or during the irradiation. Next to education and training, neutron activation analysis is the most widely used application of research reactors. Almost any reactor operating at 10-30 kilowatt of thermal power is capable of providing a sufficient neutron flux to irradiate samples for selective applications of this analysis technique. Another method of NAA by using two Am-Be isotopic neutron sources of activity $5 \mathrm{Ci}$ were used in this investigation. The accomplished gamma rays were measured using $70 \%$ HPGe spectrometer. This work demand to estimate the elements contained in cement products and its quality control. X-ray Fluorescence (XRF) measurements were done for confirming our results, and for determining the average neutron flux of $3.7 \times 10^{3} \mathrm{n} / \mathrm{cm}^{2} \mathrm{sec}$. The Natural radioactivities of these samples were measured before the analysis to know the background level of ${ }^{40} \mathrm{~K},{ }^{238} \mathrm{U}$ and $^{232}$ Th nuclei. The results investigated that NAA agree with the results of XRF and the world range of the cement concentration of the essential elements $\mathrm{Ca}, \mathrm{Al}, \mathrm{Na}, \mathrm{Fe}, \mathrm{Mn}, \mathrm{V}, \mathrm{Sr}$ and $\mathrm{Si}$.
\end{abstract}

Keywords: NAA / XRF / Natural Radioactivity / Building Material / Cement.

Language : English

Date of Publication: 30-07-2018

DOI: 10.24297/jap.v14i2.7507

ISSN: 2347-3487

Volume: 14 Issue: 2

Journal: Journal of Advances in Physics

Website: https://cirworld.com

This work is licensed under a Creative Commons Attribution 4.0 International License. 


\section{1- INTRODUCTION}

A several studies $[1,2]$ were leading to the launching of neutron activation analysis. These studies were linked to a topic of the day, which even at present is a challenging analytical task: the determination of a rare earth in one of the other elements of the rare earth series. The analyst would make use a transfer system for short and long irradiations in reactor sites with a suitable thermal neutron. The application of neutron activation analysis (NAA) to investigate archaeological problems began in the mid-1950s, when scientists at Brookhaven National Laboratory (Sayre and Dodson 1957) recognized its potential for relating artifacts to source materials through their chemical signatures.

The advantages of NAA over other analytical techniques were quickly recognized, including: (1) ease of sample preparation; (2) high precision; (3) simultaneous measurement of multiple elements; (4) outstanding reliability; and (5) excellent inter-laboratory comparability. Interest in NAA expanded throughout the 1960s, 1970s, and 1980s as a result of an increased curiosity in archaeological questions by physical scientists (e.g., Perlman and Asaro 1969; Harbottle 1976, 1982) and direct involvement of archaeologists (e.g., Bieber et al. 1976; Bishop 1975) in the application of nuclear analytical procedures. Neutron Activation Analysis (NAA) is a sensitive analytical technique useful for performing both qualitative and quantitative multi-element analysis of major, minor, and trace elements in samples from almost every conceivable field of scientific or technical interest.

For many elements and applications, NAA offers sensitivities that are superior to those attainable by other methods, on the order of parts per billion or better. In addition, because of its accuracy and reliability, NAA is generally recognized as the "referee method" of choice when new procedures are being developed or when other methods yield results that do not agree. Worldwide application of NAA is so widespread it is estimated that approximately 100,000 samples undergo analysis each year. (For more information about all analytical services at MURR). Neutron activation analysis was discovered in 1936 when Hevesy and Levi found that samples containing certain rare earth elements became highly radioactive after exposure to a source of neutrons. From this observation, they quickly recognized the potential of employing nuclear reactions on samples followed by measurement of the induced radioactivity to facilitate both qualitative and quantitative identification of the elements present in the samples.

The basic essentials required to carry out an analysis of samples by NAA are a source of neutrons, instrumentation suitable for detecting gamma rays, and a detailed knowledge of the reactions that occur when neutrons interact with target nuclei. The sequence of events occurring during the most common type of nuclear reaction used for NAA, namely the neutron capture or ( $n$,gamma) reaction. When a neutron interacts with the target nucleus via a non-elastic collision, a compound nucleus forms in an excited state. The excitation energy of the compound nucleus is due to the binding energy of the neutron with the nucleus. The compound nucleus will almost instantaneously de-excite into a more stable configuration through emission of one or more characteristic prompt gamma rays. In many cases, this new configuration yields a radioactive nucleus which also de-excites (or decays) by emission of one or more characteristic delayed gamma rays, but at a much slower rate according to the unique half-life of the radioactive nucleus. Depending upon the particular radioactive species, half-lives can range from fractions of a second to several years. In principle, therefore, with respect to the time of measurement, NAA falls into two categories: (1) prompt gamma-ray neutron activation analysis (PGNAA), where measurements take place during irradiation, or (2) delayed gamma-ray neutron activation analysis (DGNAA), where the measurements follow radioactive decay. The latter operational mode is more common; thus, when one mentions NAA it is generally assumed that measurement of the delayed gamma rays is intended.

About $70 \%$ of the elements have properties suitable for measurement by NAA. Neutron activation analysis is the most powerful analytical technique for the quantitive and the qualitative analysis. The elements to be determined in a sample are made radioactive by irradiating the sample with neutrons. The number of 
detected $\gamma$-rays of a particular energy is directly proportional to the disintegration rate of the radionuclide, which in turn is directly proportional to the amount of parent isotope in the sample and can be determined by using the absolute method [3]. Determination of trace concentration of certain elements in cement is very useful in evaluating their suitability as building materials. The need for cement is so great because cement is the main component that enters into the building construction. The drinking water are collected in concrete reservoirs then resolved to distill it from minerals. Depending on the chemistry of certain toxic or radioactive elements, some could leach into drinking water and could pose a health risk to the dwellers [4].

The most important naturally occurring radionuclide ${ }^{40} \mathrm{~K},{ }^{232} \mathrm{Th}$ and ${ }^{238} \mathrm{U}$ in Cement as part of building material were investigated $[5,6]$.These radionuclides are sources of external and internal radiation exposure in the buildings. Therefore, the dweller of houses and office buildings, where they spend about $80 \%$ of their time $[7,8]$, are exposed to radiation emitted by these radionuclides. Gamma radiation originating from ${ }^{40} \mathrm{~K},{ }^{232} \mathrm{Th}$ and ${ }^{238} \mathrm{U}$ series isotopes caused external exposure also the inhalation of the dangerous gases ${ }^{220} \mathrm{Rn}$ and ${ }^{222} \mathrm{Rn}[9,10]$. From the risk point of view, it is necessary to know the dose limits of known exposures. Simultaneously determines the natural environmental radiation level provided by these building materials, In order to assess the radiological hazards to human health, so it is important to study the radioactivity levels emitted by this material. The aim objectivities of this work are to study NAA with thermal neutrons from isotopic Am-Be neutron source to qualitify and quantify the presence of the elements in bulk cement samples from the local Egyptian market as well as to quantify the natural radionuclides in these samples.

\section{2- MATERIALS AND METHODS:}

Cement samples were collected from which have been used in Egypt. The samples are $1.5 \mathrm{Kg}$ for each weighted then dried and put into clean containers. Samples were stored for 30 days period to achieve the secular equilibrium then measure these samples $18000 \mathrm{sec}$. Indium foils were also included in the irradiation containers for monitoring the neutron flux variation along the vertical axis. The gamma-ray system is consisting of Canberra coaxial High- Purity Germanium detector (HPGe) which has a photo peak efficiency of $70 \%$ and energy resolution of $2 \mathrm{keV}$ full-width at half maximum (FWHM) for the $1332 \mathrm{keV}$ gamma-ray line of ${ }^{60} \mathrm{Co}$. A cylindrical lead shield of five $\mathrm{cm}$ thickness, which contains inner concentric cylinder of $\mathrm{Cu}$ with thickness of $10 \mathrm{~mm}$, was used to shield the detector and to reduce the effect of background. The detector was cooled to liquid nitrogen temperatures and coupled to a PC-based 8K multichannel analyzer and an ADC with Genie 2000 for data acquisition and analysis.

The calibration of the detector was carried out by using standard point sources $\left({ }^{60} \mathrm{Co},{ }^{137} \mathrm{Cs}\right.$, ${ }^{22} \mathrm{Na}$ and ${ }^{133} \mathrm{Ba}$ ). Absolute efficiency calibration curves are calculated for activity determination of the sample by using standard ${ }^{226} \mathrm{Ra}$, contained in the same cylindrical bottles as the samples. The standards and the samples were prepared with a uniform geometry. An empty bottle with the same geometry was measured for subtracting the background.

The gamma-ray transitions of energies $1120.3 \mathrm{keV}\left({ }^{214} \mathrm{Bi}\right)$ and $1764 \mathrm{keV}\left({ }^{214} \mathrm{Bi}\right)$ were used to determine the concentration of the ${ }^{238} \mathrm{U}$ series. The gamma-ray transitions of energies $911.1 \mathrm{keV}\left({ }^{228} \mathrm{Ac}\right)$ and $2614 \mathrm{keV}$ $\left({ }^{208} \mathrm{Tl}\right)$ were used to determine the concentration of the $\left({ }^{232} \mathrm{Th}\right)$ series. The $1460 \mathrm{keV}$ gamma-ray transition of ${ }^{40} \mathrm{~K}$ was used to determine the concentration of ${ }^{40} \mathrm{~K}$ in different samples as shown in table (1) and their intensities. 
Table (1) the natural radionuclides, their gamma lines used and their intensities [11].

\begin{tabular}{cccc}
\hline Parent Nuclide & Daughter Nuclide & r-ray energy $(\mathrm{keV})$ & Abundance (\%) \\
\hline${ }^{226} \mathrm{Ra}$ & ${ }^{214} \mathrm{Bi}$ & 1120.28 & 14.9 \\
& ${ }^{214} \mathrm{Bi}$ & 1764.52 & 16.07 \\
${ }^{232} \mathrm{Th}$ & ${ }^{228} \mathrm{Ac}$ & 911.16 & 29.0 \\
& ${ }^{208} \mathrm{Tl}$ & 2614.7 & 36.0 \\
${ }^{40} \mathrm{~K}$ & ${ }^{40} \mathrm{~K}$ & 1460 & 10.67
\end{tabular}

The present facility plans to use two identical isotopic radioactive neutron sources of Am-Be type. Each source has a cylindrical shape with dimensions of about $22 \mathrm{~cm}$ long and $4.4 \mathrm{~cm}$ in diameter, and has an activity of about 5 curies (185 GBq) the sources are put in an iron cylindrical barrel which filled with melted pure paraffin where the sources are isolated from the inner vertical central irradiation tube with the same paraffin material as shown in figure (1).

Figure (1): Describes the neutron irradiation facility used through the investigation.

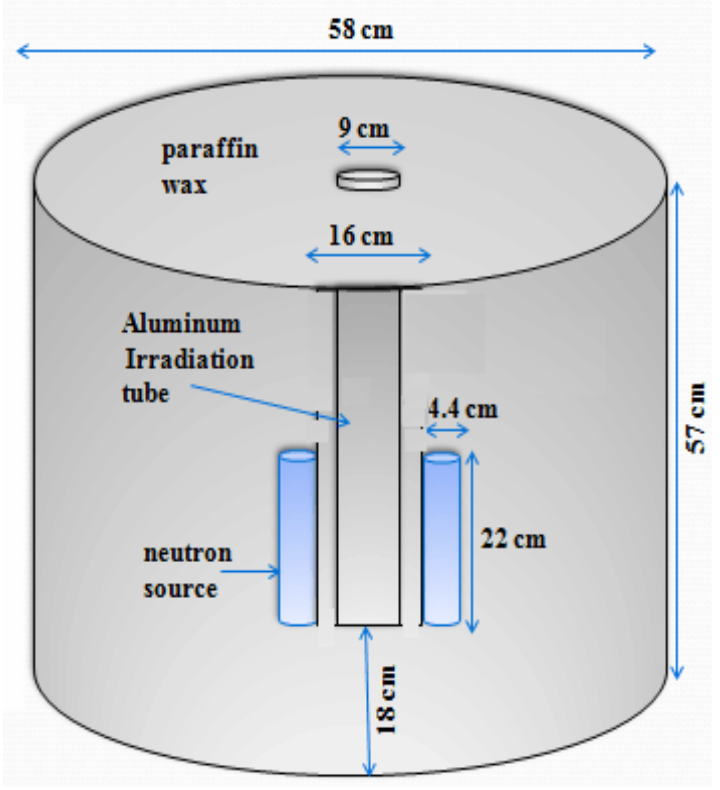

The cement analysis was performed by S2 Ranger $x$-ray spectrometer which consist of $x$-ray tube of pd mode and X-Flash silicon drift detector of resolution $<145 \mathrm{eV}$ at $\mathrm{Mn} \mathrm{K}_{\alpha}$. The samples are prepared in the pressed pellets with diameter of $20 \mathrm{~mm}$.

\section{3- RESULTS:}

\section{3-1- Natural specific activity measurement}

The activity levels for radionuclides in the measured samples are computed using the following equation [12] :- 


$$
A=\frac{C}{P W \varepsilon} \quad(\mathbf{B q} / \mathbf{k g})
$$

Where:

A the activity level of a certain radionuclide $(\mathrm{Bq} / \mathrm{kg}), \mathrm{C}$ the net count rate of the sample (counts/ seconds), $\varepsilon$ the detector efficiency for the specific gamma ray energy, $\mathrm{P}$ the absolute transition probability of gamma decay, $\mathrm{W}$ the weight of dried sample $(\mathrm{kg})$. The activity concentration of the samples is shown in table 2 where all samples are lower than world average except sample $\mathrm{S} 4$ and $\mathrm{S} 6$ for ${ }^{238} \mathrm{U}$ larger than $50 \mathrm{~Bq} / \mathrm{Kg}$.

Table (2) shows the activity concentration of different cement samples

\begin{tabular}{llccc}
\hline \multirow{2}{*}{ Material } & Mark & \multicolumn{3}{c}{ Activity concentration $(\mathrm{Bq} / \mathrm{Kg})$} \\
\cline { 2 - 5 } & & ${ }^{238} \mathrm{U}$ & ${ }^{232} \mathrm{Th}$ & ${ }^{40} \mathrm{~K}$ \\
\hline Cement & S 1 & 42.77 & 21.9 & 74.67 \\
& S 2 & 39.12 & 16.14 & 74.46 \\
& S 3 & 37.95 & 18.33 & 145.33 \\
& S 4 & 50.33 & 18.75 & 128.63 \\
& S 5 & 42.74 & 16.27 & 120.92 \\
& S 6 & 61.07 & 27.95 & 222.38 \\
\hline
\end{tabular}

\section{3-2- The radium-equivalent activity}

The distribution of ${ }^{226} \mathrm{Ra}^{2}{ }^{232} \mathrm{Th}$ and ${ }^{40} \mathrm{~K}$ in Cement is not uniform. Uniformity with respect to exposure to radiation has been defined in terms of radium equivalent activity in $\mathrm{Bq} / \mathrm{kg}$ unit, to compare the specific activity of materials containing different amounts of ${ }^{226} \mathrm{Ra},{ }^{232} \mathrm{Th}$ and ${ }^{40} \mathrm{~K}$. The Radium-equivalent activity $\left(R_{\text {aeq }}\right)$ was calculated from the following equation [13] :-

$$
R_{\text {aeq }}=A_{R a}+1.43 A_{T h}+0.077 A_{K}
$$

Where $A_{R a} A_{T h}$ and $A_{K}$ are the activity concentrations of the three radionuclide's ${ }^{226}{ }^{R a},{ }^{232} \mathrm{Th}$ and ${ }^{40} \mathrm{~K}$, respectively, expressed in $\mathrm{Bq} / \mathrm{kg}$.

\section{3-3- Radiation hazard index}

Radiation hazard index, representative level index, Defines as [13] :-

$$
I_{p r}=\left(A_{R a} / 150+A_{T h} / 100+A_{K} / 1500\right)
$$

This index can be used to estimate the level of radiation hazard associated with the natural radio nuclides in specific building construction containing cement. The Radiation hazard index varies between 0.3 and 0.5 lower than 1 which is the maximum suggested value as shown in table 3 .

Table (3) the radium-equivalent activity $\left(R_{\text {aeq }}\right)$ and Radiation hazard index of the External annual dose (EAD).

\begin{tabular}{llcc}
\hline Material & Mark & $\mathrm{Ra}_{\mathrm{eq}}(\mathrm{Bq} / \mathrm{Kg})$ & $\mathrm{EAD}(\mathrm{mSv} /$ year) \\
\hline Cement & $\mathrm{S} 1$ & 77.87 & 0.34 \\
& $\mathrm{~S} \mathrm{2}$ & 66.48 & 0.29 \\
& $\mathrm{~S} \mathrm{3}$ & 73.70 & 0.33 \\
& $\mathrm{~S} \mathrm{4}$ & 85.36 & 0.38 \\
& $\mathrm{S5}$ & 73.85 & 0.33 \\
& $\mathrm{~S} 6$ & 115.65 & 0.51 \\
\hline
\end{tabular}




\section{3-4- Neutron activation analysis}

Neutron activation analysis (NAA) was launched in Ref. (1), and has since then undergone a dramatic evolution with respect to instrumentation and applications. From a few selected examples throughout these years, it is concluded that NAA exhibits number of outstanding features which are of lasting value up to the present day. This should also be seen in the light of recent developments which are paving the way to more effective, new and specific applications. The absolute method is the most reliable for determination the elements in the samples with respect to their half-life's as shown in table 4.

Table (4) Elements determined nuclides and gamma ray energies measured [11].

\begin{tabular}{ccccccc} 
& \multicolumn{2}{c}{ Sample 1 } & \multicolumn{2}{c}{ Sample 2 } & \multicolumn{2}{c}{ Sample 3 } \\
\cline { 2 - 7 } The elements & NAA & XRF & NAA & XRF & NAA & XRF \\
\hline $\mathbf{C a}$ & 87.3 & 73.83 & 63.86 & 71.01 & 68.19 & 71.50 \\
$\mathbf{S i}$ & -- & 14.07 & -- & 17.14 & -- & 17.07 \\
$\mathbf{A l}$ & 5.59 & -- & 5.95 & 4.13 & 4.60 & 3.77 \\
$\mathbf{M g}$ & -- & -- & -- & 1.70 & - & 2.51 \\
$\mathbf{M n}$ & 0.23 & 0.34 & 0.07 & -- & 0.13 & -- \\
$\mathbf{~ a a}$ & 0.69 & -- & 0.49 & 2.82 & 0.34 & 1.56 \\
$\mathbf{F e}$ & -- & 8.37 & -- & 3.73 & -- & 3.59 \\
$\mathbf{V}$ & 0.01 & 0.02 & -- & -- & -- & -- \\
$\mathbf{S r}$ & 0.53 & 0.24 & -- & -- & -- & -- \\
\hline
\end{tabular}

The analysis of the samples are performed by NAA and XRF where the results show that the concentration of $\mathrm{Ca}$ element varies from 63.8 to 87.3 in addition to other elements are found in the sample like $\mathrm{Si}, \mathrm{Al}$, $\mathrm{Mg}, \mathrm{Mn}, \mathrm{Na}, \mathrm{Fe}, \mathrm{V}$ and $\mathrm{Sr}$ as shown in table 5.

Table (5) the comparison between the analyses of NAA with XRF:

\begin{tabular}{lccc}
\hline & & & \\
& Element & Guclide & Half-life \\
& Used & measured, $\mathrm{keV}$ & \\
\hline $\mathrm{Ca}$ & & & \\
$\mathrm{Al}$ & ${ }^{49} \mathrm{Ca}$ & 3084.5 & $8.72 \mathrm{~m}$ \\
$\mathrm{Na}$ & ${ }^{28} \mathrm{Al}$ & 1779.0 & $2.24 \mathrm{~m}$ \\
$\mathrm{Mn}$ & ${ }^{24} \mathrm{Na}$ & $1368.6,2754$ & $14.96 \mathrm{~h}$ \\
$\mathrm{Sr}$ & ${ }^{56} \mathrm{Mn}$ & $846.8,1810.7,2113.1$ & $2.58 \mathrm{~h}$ \\
$\mathrm{~V}$ & ${ }^{87} \mathrm{Sr}$ & 388.4 & $2.81 \mathrm{~h}$ \\
& ${ }^{52} \mathrm{~V}$ & 1434.1 & $3.75 \mathrm{~m}$ \\
\hline
\end{tabular}




\section{3-5- Present and future role of neutron:}

The above given measurements represent only some applications reported since the launching of NAA. More information can for instance be found in the series of several proceeding and works in neutron activation analysis e.g. Ref. [1, 2, 9 and 19], from all this, it is clear that the success of NAA was due to number of outstanding features. Indeed, its excellent sensitivity for many element, its theoretical foundation enabling to identify and predict all sources of systematic or radon variation. And its analysis of e.g. Cement has been carried out, all these combined features made NAA to very powerful and reliable analytical tool.

In spite of these top-level performances, it should not be denied that in recent years NAA was seriously waylaid by a number of developments and circumstances. Indeed one should use NAA for what it can do, and one should realize that some of its features are of lasting value and even unique up to the present day. The present and feature role of NAA should be interpreted in the light of new insights into its power. This especially refers to the fact that it is an accurate and traceable method, with a physically different basis compared to other techniques, and with a built in possibility of self verifications since in many cases results for an element can be obtained via different gamma lines of different isotopes Ref $[15,14]$. This makes NAA to a references method, which is eminently suited for the calibration of other analytical techniques Ref. [16] for the certification of references materials. It is believed that the above measurements will lead to a situation where NAA will continue to fulfill its specific and valuable role in the arsenal of the available analytical techniques in table 6 .

Table (6) The Comparison of elements concentration of the world cement with the local cement Measured by the available techniques:-

\begin{tabular}{cccccc}
\hline $\begin{array}{c}\text { Techniqu } \\
\mathbf{e}\end{array}$ & XRF & PGAA & NAA & XRF & NAA \\
Elements & {$[\mathbf{1 7 ]}$} & {$[\mathbf{1 8}]$} & {$[\mathbf{1 9 ]}$} & $\begin{array}{c}\text { This } \\
\text { study }\end{array}$ & $\begin{array}{c}\text { This } \\
\text { study }\end{array}$ \\
\hline $\mathbf{C a}$ & 67.5 & 64.0 & 63.2 & 73.8 & 87.3 \\
$\mathbf{S i}$ & 21.6 & 22.0 & 21.9 & 14.0 & --- \\
$\mathbf{A l}$ & 4.5 & 4.0 & 5.1 & & 5.59 \\
$\mathbf{F e}$ & 3.6 & 2.2 & 2.8 & 8.37 & --- \\
$\mathbf{M g}$ & 1.5 & 0.21 & 2.3 & --- & -- \\
$\mathbf{N a}$ & 0.19 & 0.31 & --- & --- & 0.69 \\
$\mathbf{K}$ & 0.55 & 1.96 & --- & --- & --- \\
$\mathbf{S}$ & 0.05 & --- & 2.5 & 2.72 & --- \\
$\mathbf{T i}$ & 0.2 & --- & --- & 0.40 & --- \\
$\mathbf{M n}$ & ---- & ---- & --- & 0.34 & 0.23 \\
$\mathbf{S r}$ & ---- & --- & --- & 0.24 & 0.53 \\
$\mathbf{V}$ & 0.02 & $\ldots \ldots$. & $\ldots$ & $\ldots .$. & 0.01 \\
\hline
\end{tabular}




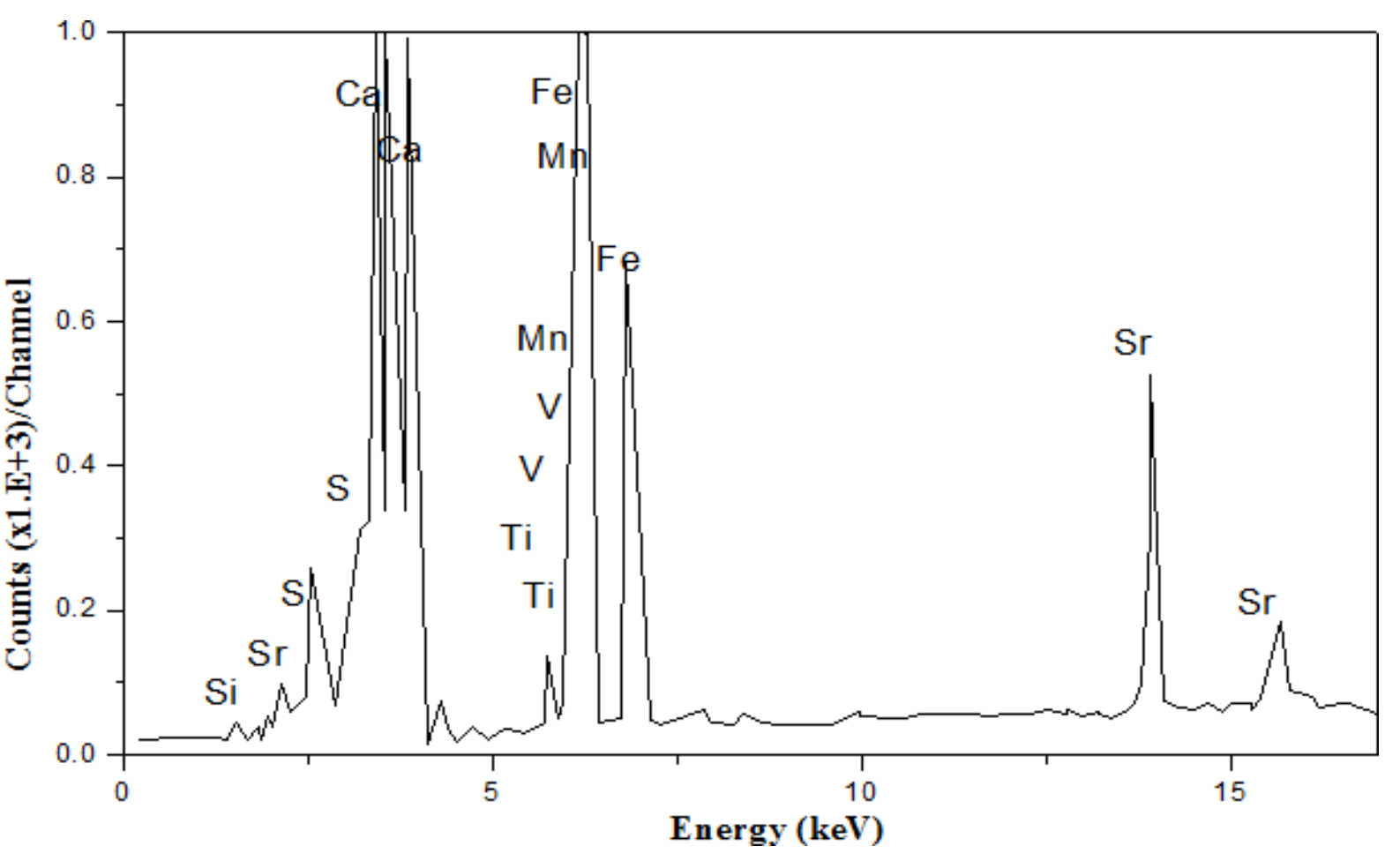

Figure (2): illustrates the analysis of cement sample by XRF Technique.

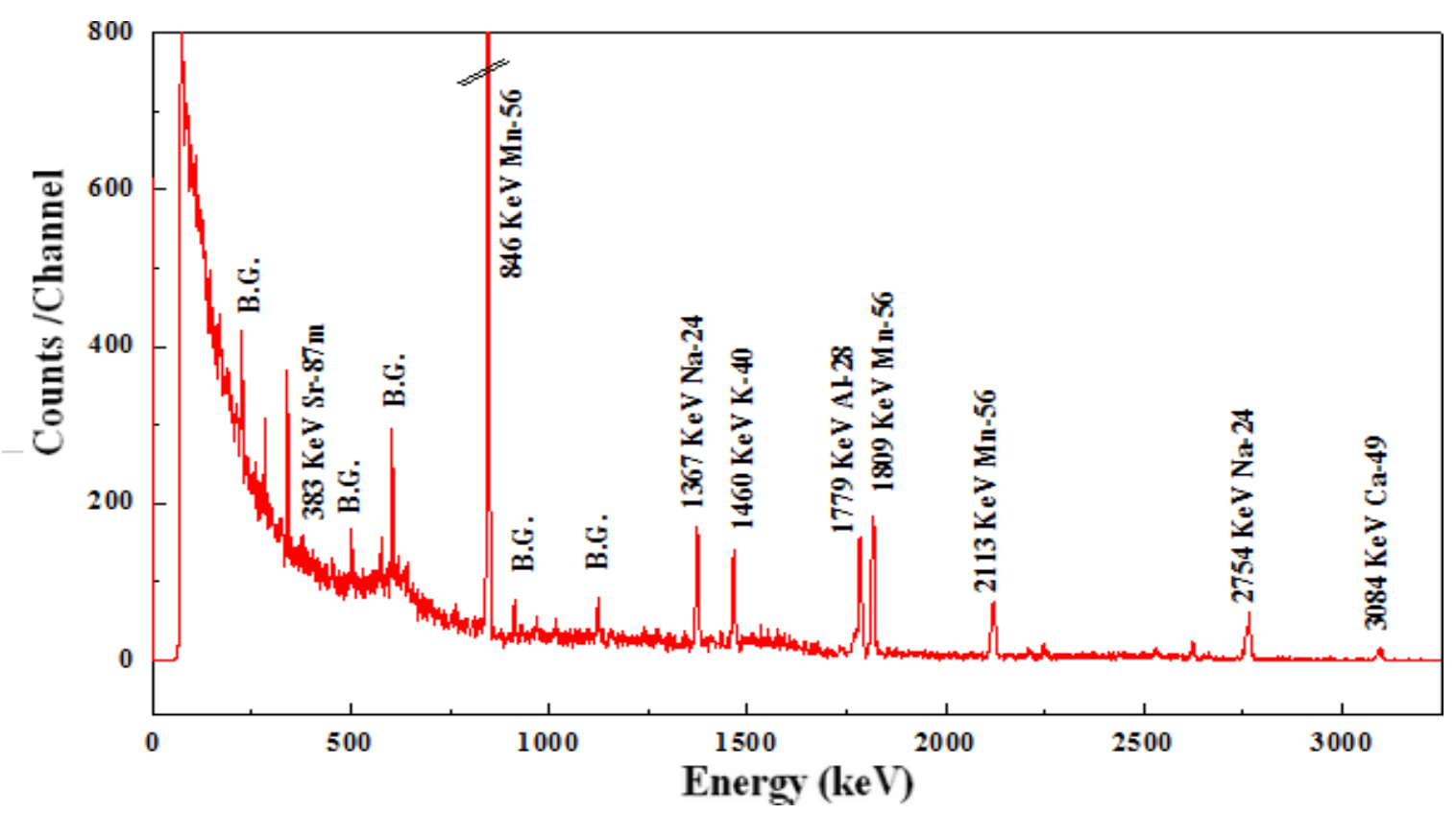

Figure (3): illustrates the analysis of cement sample by NAA Technique. 


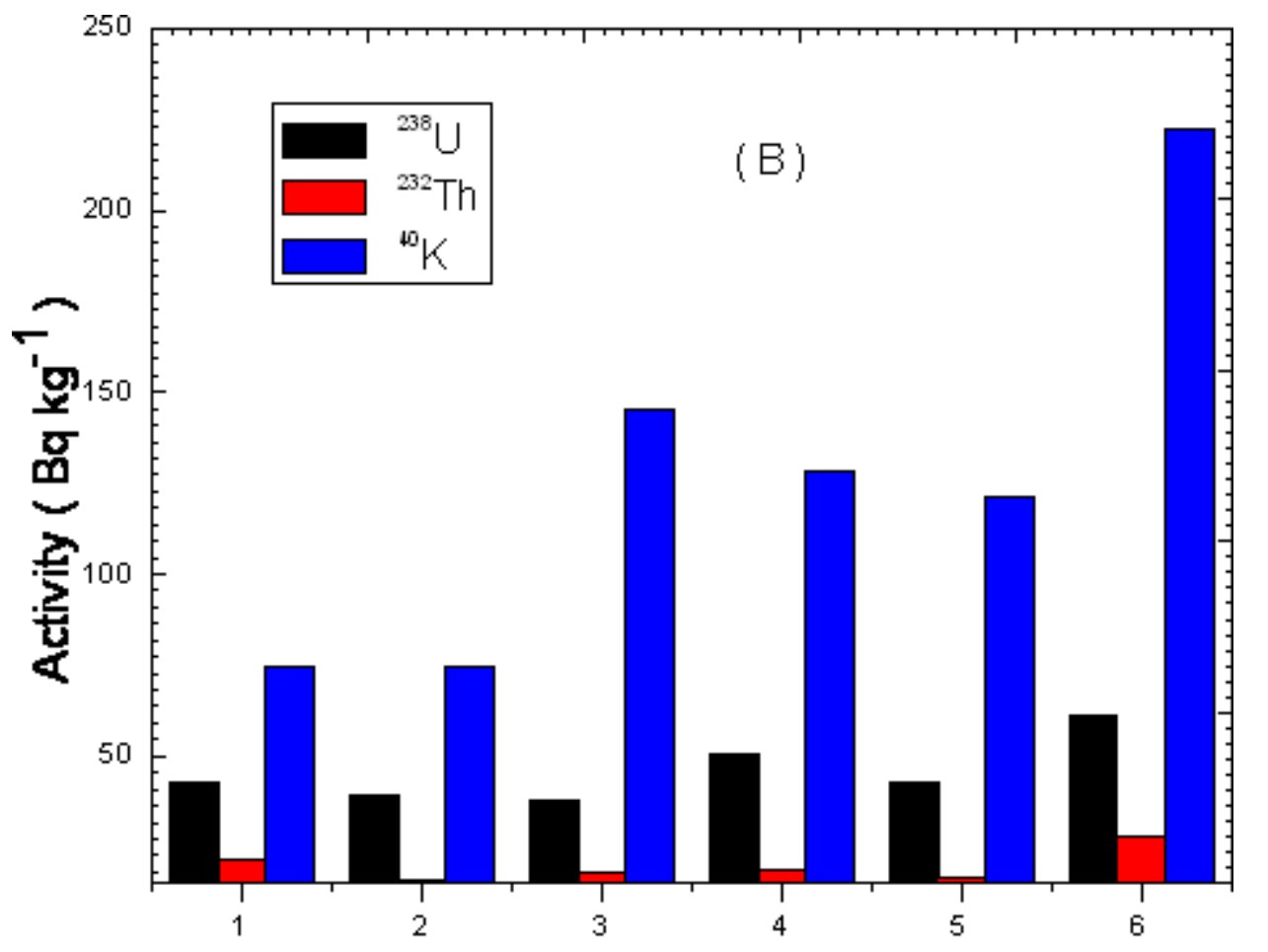

Sample No.

Fig. (4): ( A ) Radium equivalent activity in collected samples. (B) The ${ }^{238} \mathrm{U},{ }^{232} \mathrm{Th}$ and ${ }^{40} \mathrm{~K}$ concentration in different samples.

\section{4- Conclusion:}

The activity concentrations for ${ }^{238} \mathrm{U},{ }^{232} \mathrm{Th},{ }^{40} \mathrm{~K}$ and Ra-equivalent activity are shown in Fig. $(4 \mathrm{~A}, \mathrm{~B})$. The activity concentrations for ${ }^{238} \mathrm{U}$ ranged from 37.95 to $61.07 \mathrm{BqKg}^{-1}$, with an average of $45.65 \mathrm{~Bq} \mathrm{Kg}^{-1},{ }^{232} \mathrm{Th}^{2}$ ranged from 16.14 to $27.95 \mathrm{BqKg}^{-1}$, with an average $19.89 \mathrm{BqKg}^{-1}$ and variation in ${ }^{40} \mathrm{~K}$ activities ranges from 74.46 to $222.38 \mathrm{BqKg}^{-1}$ with an average $127.73 \mathrm{BqKg}^{-1}$, respectively. In this work, a NAA method for the cement analysis has been carried out. An important parameter for the quality control of art building is the calcium proportion present in the cement. The neutron activation seems to be the more reliable and practical method to determine the concentration of the elements in bulk samples and nondestructively. Isotopic neutron sources like $\mathrm{Am}-\mathrm{Be}$, has sufficient flux for the qualitative and the quantitative neutron activation analysis of bulk samples with large amounts in the range of kilograms. Further, this method is easily applied if minimal condition for radioprotection is respected and the cost is reasonable over destructive techniques is taken into account.

\section{5- REFERENCES:}

[1] Levi H., Semi centennial lecture, addendum to the proceedings of 7 th inter. conference of modern trends in the activation analysis, Copenhagen, Denmark, (1996), June 23-27

[2] Kolesov G. M and Shubina N. A.g J. of Analyt. Chem. (2003). 58, 307.

[3] KAFALA S. I., MACMAHON T. D.; J. RadioanI.Nucl. Chem., (2007), 271(2) 507.

[4] Khrbish Y. S., Abugassa I. Benfaid O., N. and Bashir A. A.; J. Radioanal. Nucl. Chem.; (2007). 271, 63

[5] Ahmed N.K; J. Environ. Radioact.; (2005) 83, 91 
[6] Higgy R. H., El-Tahawy M.S., Abdel-Fattah A.T. and Al-Akabawy U.A.; J. Environ. Radioact.; (2000) 50, 253.

[7] PAPASTEFANOU C., Stoulos S. and Manolopoulou M.; J. Radioanl. Nucl. Chem.; (2005) 266, 367.

[8] El-Taher A., Makhluf S., Nossair A. and AbdelHalim A.S.; Appl. Radiat.and Isot.; (2010) 68 -169 .

[9] Munazza Faheema, Mujahid S.A. and Matiullah; Radiat. Measur.; (2008) 43, 1443.

[10] Turhan Ş.; Environ J.. Radioact.; (2008) 99, 404.

[11] Tables for Practical aspects of operating neutron activation analysis laboratory; (1990) No.564, IAEA, VIENNA,

[12] Amrani D., Tahta M; Appl. Radiat.and Iso.; (2001) 54, 687.

[13] Ngachina M. Garavaglia M., Giovani C., Kwato Njock M.G. and. Nourreddine A; Radiat. Measur.; (2007) 42,61 .

[14] A.R. Byrne, Fresenius; J. Anal. Chem. 345, 144 (1993).

[15] J.J.M. DeGoeij, J. R. W. Woittiez, J. Radioanal. Chem. 168, 429 (1993).

[16] F. DeCorte, A. Simonitds, F. Bellemans, M.C. Freitas, S. Jovanovic, B. Smodis, G. Erdtmann, H. Perti, A. De Wispelaere, J. Radioanal. Nucl. Chem. 169,125 (1993).

[17] C.S. Lim , J.R. Tickner, B.D. Sowerby, D.A. Abernethy, A.J. McEwan,S. Rainey, R. Stevens, C. Manias and D. Retallack ; Appl. Radiat. and Iso.; 54, 11(2001).

[18] A. A.Naqvi, M.A.Garwan, M.Maslehuddin, M.M.Nagadi, O.S.B.Al-Amoudi, Khateeb-ur- Rehman and M.Raashid..; Appl. Radiat. and Iso.; 67, 1707(2009).

[19] C.W. Wolhuter, J. Turkstra and R.M. Morris; Methods and apparatus laboratories manual, 201(1974). 